\title{
A auto-estima e o não-verbal dos pacientes com queimaduras
}

\author{
THE SELF-ESTEEM AND THE NONVERBAL SIGNS OF THE BURN PATIENTS
}

\section{LAAUTOESTIMA Y EL NO VERBAL DE LOS PACIENTES CON QUEMADURAS}

\author{
Milena Froes da Silva ${ }^{1}$, Maria Júlia Paes da Silva²
}

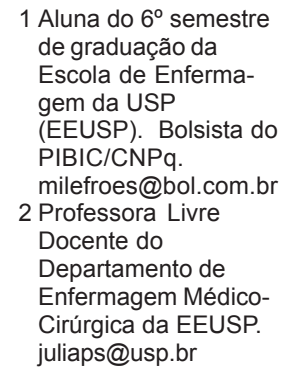

\author{
RESUMO \\ Esta pesquisa teve como \\ objetivos identificar o grau de \\ auto-estima dos pacientes do \\ Ambulatório de Seqüelas de \\ Queimaduras do HC-FMUSP \\ e identificar os sinais não- \\ verbais emitidos pelos \\ pacientes, quando questio- \\ nados sobre sua auto-estima. \\ Realizado com 80 pacientes \\ (54 mulheres e 26 homens) \\ atendidos na unidade durante \\ o mês de fevereiro de 2002, o \\ projeto foi aprovado pelas \\ Comissões de Ética em \\ Pesquisa da EEUSP e do \\ HC-FMUSP e as entrevistas \\ individuais com os pacientes \\ baseadas em uma escala para \\ avaliação de auto-estima \\ validada no Brasil e na \\ classificação de sinais não- \\ verbais proposta por Silva. \\ Dentre os resultados, \\ verificamos que $18,75 \%$ \\ pacientes apresentam baixa \\ auto-estima, 32,50\% média \\ auto-estima e 48,75\% \\ pacientes alta auto-estima. $O$ \\ complemento foi a função dos \\ sinais não-verbais mais \\ freqüente entre os pacientes.
}

\section{PALAVRAS-CHAVE}

Auto-estima.

Queimaduras.

Comunicação.

Empatia.

\begin{abstract}
This research aimed to identify the self-esteem degree and the nonverbal signs of the Burn Center patients at HC-FMUSP. Those signs complement, contradict or demonstrate the patients'feelings when they are asked about their selfesteem. The project was accomplished with 80 patient (54 women and 26 men) attended in the hospital in February 2002. It has been approved by the Commissions of Ethics on Research of EEUSP and HC-FMUSP. The individual interviews with the patients were based on the scale of self-esteem validated in Brazil and also based on the classification of the nonverbal signs proposed by Silva. Through the results we verified that $18.75 \%$ patients present low self-esteem, $32.50 \%$ medium self-esteem and $48.75 \%$ high self-esteem. We also concluded that the complement was the function of the nonverbal signs, more often during the interviews.
\end{abstract}

\section{KEYWORDS}

Self-concept.

Burns.

Communication.

Empathy.

\section{RESUMEN}

Esta investigación tuvo como objetivos identificar el grado de autoestima de los pacientes de Consulta Externa de Secuelas de Quemaduras del HC-FMUSP e identificar las señales no verbales emitidas por los pacientes, al ser interrogados sobre su autoestima. Realizado con 80 pacientes (54 mujeres y 26 hombres) atendidos en la unidad en el mes de febrero del 2002, el proyecto fue aprobado por las Comisiones de Ética en Investigación de la EEUSP y del HC-FMUSP y las entrevistas individuales con los pacientes basadas en una escala para evaluación de autoestima validada en Brasil y en la clasificación de señales no verbales propuesta por Silva. Entre los resultados, verificamos que el $18.75 \%$ de pacientes presentan baja autoestima, $32.50 \%$ media autoestima y $48.75 \%$ de pacientes alta autoestima. El complemento fue la función de las señales no verbales más frecuente entre los pacientes.

\section{PALABRAS CLAVE}

Autoimagem.

Quemaduras.

Comunicación.

Empatía. 


\section{INTRODUÇÃO}

Comunicar vem do latim communicare, que significa transmitir informação, fazer saber, participar, fazer contato, partilhar $^{(1)}$. O processo de comunicação é um fluxo contínuo e circular de energia, portanto um processo dinâmico, porque seus elementos interagem e, continuamente, há influência de uns sobre os outros ${ }^{(2)}$.

Nas ciências médicas e paramédicas o processo da comunicação é de extrema relevância. O seu significado semântico pode variar, desde um simples gesto de olhar para o paciente, até mesmo o envolvimento e a maneira de execução de técnicas, em uma melhor conceptualização do contexto que se apresenta ${ }^{(3-6)}$. Infelizmente, o chamado instrumento básico da terapêutica de Enfermagem - a comunicação - recebeu menor atenção ao longo do desenvolvimento da profissão, o que fez com que os profissionais na assistência ao paciente restrinjam-se ao trabalho mecânico e impulsivo do cuidado físico do paciente, diminuindo seu espaço profissional e sua atuação e inibindo uma comunicação efetiva. É por meio da comunicação estabelecida com o paciente que podemos compreendê-lo no seu todo: o pensar, o agir, o sentir... para assim identificar os problemas que sente e qual o valor que atribui a eles. Segundo Stefanelli ${ }^{(2)}$, o enfermeiro deve ser hábil no processo de comunicação com o paciente, $\mathrm{e}$ para isto é necessário adquirir uma base teórica sobre comunicação geral e comunicação interpessoal, uma vez que comunicação, enfermeiro e paciente formam o tripé que permite a excelência do cuidar em Enfermagem.

Podemos classificar a comunicação interpessoal em verbal e não-verbal. Na verbal faz-se uso das palavras por elas mesmas na relação entender e fazer-se entender; já a não verbal, é aquela que não envolve a verbalização por ela mesma, compreendendo, por exemplo, a linguagem do corpo, do toque, a distância mantida entre os profissionais e pontos que influenciam o seu relacionamento enfermeiro-paciente, contribuindo para a compreensão do próprio paciente, seus medos, seus traumas, sua adesão ao tratamento oferecido.

Muitas vezes, o desconhecimento consciente deste tipo de linguagem, impede sua percepção e, segundo Blonds, Jackson apud
Silva ${ }^{(7)}$, é a percepção que dá significado às nossas interações com o outro. De acordo com Silva ${ }^{(7)}$, quanto maior for a capacidade do enfermeiro de decodificar corretamente $o$ não-verbal, maior será sua chance de emitir adequadamente os sinais não-verbais, de ser coerente na sua relação com o paciente, de potencializar sua capacidade de compreendêlo e de ser comunicador e orientador. O desafio da comunicação é que o que é dito, muitas vezes contradiz o que é expresso pelo corpo. Davis $^{(8)}$, estudiosa do tema, afirma que as palavras não são tudo, que são apenas o início, pois além delas está o solo firme sobre o qual se constroem as relações humanas: a comunicação não-verbal.

As quatro funções básicas da comunicação não-verbal são: complementar o verbal (quando existe coerência entre os dois códigos de expressão), substituir o verbal, contradizê-lo e demonstrar os sentimentos ${ }^{(9)}$. Quando alguém tem alterada, bruscamente, a sua imagem, como os pacientes queimados, há alteração na sua auto-estima? Estas alterações podem ser evidenciadas através de contradições no seu discurso e no seu comportamento? A presente pesquisa destinouse a discutir aspectos da comunicação não-verbal e auto-estima de pessoas com queimaduras.

Este assunto despertou o interesse da aluna participante deste estudo, muito antes de cursar a faculdade e de ter o primeiro contato com os pacientes, pois percebia em si uma certa sensibilidade em notar o não-verbal das outras pessoas. Ao conversar com colegas, notava que seus olhos, sua expressão facial, sua postura, exprimiam, muitas vezes, um sentimento que não estava sendo verbalizado durante o diálogo. Isto despertou muito a sua curiosidade, já que atribuía esta percepção à intuição. Ao tomar conhecimento de que esta "intuição" é o conhecimento consciente de que há uma outra forma de exprimir desejos, sentimentos e valores, que não utiliza palavras, mas que se faz entender, e que esta é denominada de comunicação não-verbal, compreendeu que possuía sensibilidade na percepção do não-verbal e que isto poderia ser usado como um importante instrumento da terapêutica em Enfermagem.

Segundo Branden ${ }^{(10)}$, a auto-estima reflete o julgamento implícito da nossa capacidade de lidar com os desafios da vida,
A auto-estima e o não-verbal dos pacientes com queimaduras 
Milena Froes da Silva Maria Júlia Paes da Silva

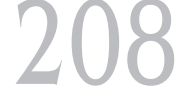

Rev Esc Enferm USP 2004; 38(2):206-16. sentindo-nos confiantemente adequados a ela. Desenvolver a nossa auto-estima é expandir nossa capacidade de ser feliz. Quanto maior ela for, maiores serão as nossas possibilidades de manter relações saudáveis, em vez de destrutivas. $O$ autor afirma que a autoestima, seja qual for o nível, é uma experiência íntima; reside no cerne do nosso ser. É o que $e u$ penso e sinto sobre mim mesmo, não o que o outro pensa ou sente sobre mim; ela é o estado da pessoa que não está em guerra consigo mesma ou com os outros. O mesmo autor refere que há duas palavras que descrevem bem o que podemos fazer para elevar a nossa auto-estima, são elas: viver conscientemente. Para tal, é necessário se fazer o uso adequado da nossa consciência e isto é um ato de escolha. Viver conscientemente significa estar cônscio de tudo o que afeta os nossos atos, valores e metas, e comportar-se de acordo com o que vemos e sabemos.

As pessoas sempre falam sobre como é difícil aceitar os próprios defeitos, porém alguém deveria falar sobre como é difícil aceitar as próprias virtudes. A maior implicação disto é que muitos poderão dizer: "Se eu aceitar o fato de que gosto de mim, terei de me comportar de forma diferente!". Ou: "Se eu aceitar o fato de que gosto de mim, terei de permanecer demasiado consciente!". Quando se é incapaz de viver conscientemente, o nível mais profundo e mais primitivo do ser tende a voltar-se contra nós, gerando dor no nível da auto-estima.

Branden ${ }^{(10)}$ afirma que as mentiras mais devastadoras para a nossa auto-estima não são tanto as que contamos, mas as que vivemos. Vivemos uma mentira quando distorcemos a realidade da nossa experiência ou a verdade do nosso ser. Vivo uma mentira quando finjo um amor que não sinto; quando finjo uma indiferença que não sinto; quando me mostro mais do que sou; quando finjo uma cegueira que nega minha consciência; quando rio e quero chorar; quando deixo meu silêncio concordar com convicções que não compartilho. A boa auto-estima exige congruência - o que significa que o eu interior está de acordo com o eu manifesto no mundo.

Happé ${ }^{(1)}$ refere que viver com autenticidade não significa dizer compulsivamente a verdade, não significa revelar todos os pensamentos ou sentimentos, mas reconhecêlos em nós. A autenticidade se expressa grandemente em pessoas com elevada autoestima e estas conseguem amigos melhores e mais confiáveis, porque elas inspiram as outras pessoas a corresponderem à sua autenticidade.

Se proporcionarmos as pessoas uma oportunidade, para que possam desenvolver a sua boa auto-estima, conseqüentemente a visualização da sua auto-imagem será positiva, já que ela não estará mais em guerra consigo mesma ou com o mundo. A assistência de enfermagem deverá estar fundamentada, na percepção do indivíduo tal como ele se vê - sua imagem corporal. Quando falamos de auto-imagem, nos referimos à forma como cada um se vê no seu "espelho interior". Sapountzi-Krepia et al ${ }^{(12)}$ afirmam que a imagem do corpo é uma imagem conceitual, uma parte do autoconceito, e envolve atitudes que o ser experimenta como pertencendo ao corpo, habilidades e emissão do poder físico. Doenças orgânicas que afetam a estrutura do corpo de uma pessoa podem alterar sua imagem, e as reações a tais alterações são influenciadas pelos padrões de desenvolvimento, família, atitudes culturais, como também pelo tipo de tratamento. Os autores referem que as reações do corpo frente à mudança da imagem estão relacionadas com a natureza dessa alteração e com o significado dessa mudança para a pessoa; os pacientes respondem as perdas de modo pessoal e a família, amigos e, principalmente, os profissionais da saúde podem ajudá-los a aceitar essa imagem do corpo, agora, modificada.

Segundo Duarte ${ }^{(13)}$, o belo, ao longo da história, sempre simbolizou algum objeto, cena ou situação que agradasse aos olhos, porém o ato de compreensão e de atuação, fundada numa forma teórica, configura um todo harmônico equilibrado, que também é percebido como belo. Assim, reforçamos que a elevação da auto-estima não depende da beleza que é refletida no espelho, mas da forma como ela é vista neste mesmo espelho. Como afirma o escritor Fernando Pessoa apud

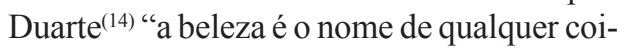
sa que não existe/ que dou às coisas em troca do agrado que me dão."

Andrade, Angerami ${ }^{(14)}$ afirmam que o conceito de auto-estima tem sido estudado e considerado como um importante indicador de saúde mental. Lembram da necessidade de aplicação de instrumentos precisos que permitam avaliar a necessidade de auto-estima 
de cada indivíduo; e que o uso de escalas como forma de investigação, tem sido crescente na Enfermagem, possibilitando uma aplicabilidade prática. Há um método de avaliação da medida do sentimento de auto-estima proposto por Dela Coleta, Dela Coleta ${ }^{(15)}$, que consiste no uso de uma escala, validada no Brasil, que permite-nos, baseados em afirmações referentes a acontecimentos da vida diária, estabelecer graus de adequação à autoestima. Fundamentada nesta escala e atenta ao não-verbal dos pacientes, é que pretendemos atingir os objetivos deste estudo.

\section{OBJETIVOS DO ESTUDO}

Esta pesquisa teve como objetivos:

- identificar o grau de auto-estima dos pacientes do Ambulatório de Seqüelas de Queimaduras do HC-FMUSP;

- identificar os sinais não-verbais emitidos pelos pacientes, quando questionados sobre sua auto-estima, que complementam, contradizem ou demonstrem sentimentos.

\section{MÉTODO}

Tipo de estudo - É um estudo exploratório descritivo, transversal e de campo.

Local do estudo - Ambulatório de Seqüelas de Queimaduras da Disciplina de Cirurgia Plástica do HC-FMUSP.

População - 80 pacientes adultos (54 mulheres e 26 homens) atendidos na unidade durante o mês de fevereiro de 2002, conscientes e que aceitaram participar do estudo. O critério foi: paciente que sofreu queimadura há mais de 1 ano.

Procedimentos de coleta de dados - O projeto de pesquisa foi analisado e aprovado pelas Comissões de Ética em Pesquisa da Escola de Enfermagem da Universidade de São Paulo e do Hospital das Clínicas da Faculdade de Medicina da Universidade de São Paulo em julho de 2001 e fevereiro de 2002, respectivamente. Após aprovação pelas Comissões de Ética, os pacientes foram abordados individualmente, no Ambulatório, durante os meses de fevereiro e março de 2002, quando iam para suas consultas e, após esclarecimento dos seus objetivos, os que concordaram participar do estudo assinaram o Termo de Consentimento Livre e Esclarecido, conforme Resolução 196/96 do Ministério da Saú- de. Foi assegurado o esclarecimento de todas as dúvidas que poderiam surgir sobre a pesquisa e que o participante poderia retirar sua participação a qualquer momento, sem prejuízo do seu tratamento. Esclarecido ainda que o informante não seria identificado e que os dados que poderiam revelá-lo não seriam divulgados em qualquer relatório ou publicação. As entrevistas abordaram a autoestima dos pacientes, avaliada pela escala de auto-estima de Dela Coleta; Dela Coleta ${ }^{(15)}$, já validada pelo autor, que é constituída de 15 afirmações do tipo certo-errado, as quais, a partir de um gabarito, resultam num escore de auto-estima do paciente (os autores descrevem como aplicá-la e o gabarito de leitura). As classificações de auto-estima (AE) equivalem a uma pontuação de 0 a 5 para baixa $\mathrm{AE}$, de 6 a 10 para média $\mathrm{AE}$ e de 11 a 15 para alta AE. Além do Escore de Auto-Estima, coletou-se dados, por meio de entrevista, como nome (iniciais), idade, sexo, local da queimadura, número de áreas atingidas e tempo de queimado. A pesquisadora gravou as respostas, as observações verbais feitas pelos pacientes a cada afirmação e ficou atenta ao não-verbal demonstrado por eles durante as questões, baseada na classificação do nãoverbal proposta por $\operatorname{Silva}^{(9)}$, que descreve comportamentos que demonstram sentimentos verbalizados. Dessa classificação, foram observados sinais não-verbais da cinésica (linguagem do corpo), da proxêmica (distância mantida entre as pessoas e o uso de seu espaço pessoal) e do paraverbal (pausas, grunhidos, hesitações, ênfases no falar).

Tratamento dos dados - Efetuadas as entrevistas, analisamos quantitativamente as respostas contidas no questionário, de acordo com o gabarito da Escala de Auto-Estima de Dela Coleta, Dela Coleta ${ }^{(15)}$; avaliamos também a existência de dependência entre $\mathrm{AE}$ e as variáveis quantitativas do estudo. Os procedimentos estatísticos adotados foram:

- Intervalos de Confiança de 95\%, usados para estimar médias e porcentagens reais de alguns eventos de interesse do estudo;

- Os Coeficientes de Correlação Ordinal de Spearman e Linear de Pearson, usados na avaliação da existência de dependência entre $\mathrm{AE}$ e as variáveis quantitativas do estudo;

- Os Teste de Mann Whitney para amostras independentes, usado na avaliação da
A auto-estima e o

não-verbal dos

pacientes com

queimaduras 
Milena Froes da Silva Maria Júlia Paes da Silva dependência entre a $\mathrm{AE}$ e as variáveis qualitativas dicotômicas do estudo;

- O Teste Qui Quadrado foi usado para avaliar a significatividade da associação entre as variáveis nominais do estudo.

Quando, no estudo de variáveis dicotômicas, mais de $20 \%$ das freqüências esperadas foi inferior a 5 , a associação foi avaliada através do Teste Exato de Fisher. Neste estudo toda correlação, associação ou diferença cujo P-Value foi inferior a 0,05 foi considerada estatisticamente significativa ${ }^{(16)}$.

Analisamos também, pela observação visual do não-verbal expresso pelos pacientes durante as entrevistas, e de acordo com a classificação proposta por Silva ${ }^{(10)}$, os sinais que complementaram, contradisseram e demonstraram sentimentos. A análise desses registros foi validada por especialista do tema, que reviu as anotações feitas para assegurar a fidedignidade, apesar da autora ter sido previamente treinada para a coleta de dados.

Segundo Duarte ${ }^{(13)}$, os sentimentos são evidências estruturadas da realidade, isto é, conscientizações da interação entre o organismo e ambiente; são apreensões diretas da situação na qual nos encontramos. Assim os pacientes com alteração da auto-imagem, poderão refletir com maior facilidade sua aversão à situação em que se encontram.

\section{APRESENTAÇÃOE DISCUSSÃO DOS RESULTADOS}

Quanto ao primeiro objetivo, que foi identificar o grau de auto-estima dos pacientes do Ambulatório de Seqüelas de Queimaduras do HC-FMUSP, foram feitas análises quantitativas e cruzamento dos dados obtidos na entrevista, a fim de mensurar o grau de auto-estima (AE) dos pacientes e verificar se o mesmo possui alguma relação com as variáveis já mencionadas (idade, sexo, local, tempo de queimadura e números de queimaduras).

$\mathrm{Na}$ caracterização da clientela, observamos que para a variável Idade há a predominância de pacientes com faixa etária de 15 a 29 anos nos três níveis de auto-estima estudados, a saber, $53,33 \%$ no grupo de pacientes com baixa auto-estima, $46,15 \%$ no grupo de média auto-estima, $46,15 \%$ no grupo de alta auto-estima e $47,50 \%$ no conjunto dos pacientes; com variações respectivamente dadas por 19 a 64 anos, 15 a 76 anos, 15 a 88 anos. $\mathrm{O}$ exame dos intervalos de confiança de $95 \%$ sugere não haver diferença estatisticamente significativa entre as médias citadas.

Quanto à variável Sexo, observa-se (a despeito de prever evidência de que a média de AE dos homens supera a média das mulheres) predomínio de mulheres em todos os níveis de auto-estima $(85,71 \%$ para baixa AE, $69,23 \%$ para média $\mathrm{AE}$ e $60,00 \%$ para alta $\mathrm{AE}$ ). Tal resultado sugere a concentração dos valores de AE masculino nos limites superiores de cada nível.

Na variável Local da Queimadura, vemos que MMSS (membros superiores) e tórax são os locais onde mais ocorreram as queimaduras, com 21,91\% das citações para MMSS e $17,13 \%$ para o tórax. Com relação a qualquer classificação de auto-estima, encontramos as maiores porcentagens de queimaduras nessas regiões também, como podemos observar: no grupo de pacientes com baixa autoestima (26,09\% MMSS e 19,57\% tórax), no grupo com média auto-estima (17,39\% MMSS e $16,30 \%$ tórax) e no grupo com alta autoestima (23,89\% MMSS e 16,81\% tórax).

Na variável Número de Áreas Atingidas, quantificamos as lesões de acordo com a classificação utilizada na variável Local da Queimadura, ou seja, cabeça, face, pescoço, tórax, abdômen, pelve, dorso, MMSS e MMII, assim pudemos observar que a maioria dos pacientes apresentam entre 2 a 4 locais com queimaduras ( 45 pacientes $=56,25 \%$ ). Isto se mantêm para os pacientes com baixa autoestima $(66,67 \%)$, com média auto-estima $(46,15 \%)$ e com alta auto-estima (58,97\%). As variações são, respectivamente, 1 a 6, 1 a 9, 1 a 8. Mais uma vez a análise dos intervalos de confiança de $95 \%$ sugerem não existir diferença estatisticamente significativa entre as médias citadas.

A variável Tempo de Queimado mostranos que o tempo médio de queimadura dos pacientes varia de 0.06 à 10.05 anos (56,25\%); e esta variável também se aplica nos diferentes níveis de auto-estima, com citação de $66,67 \%$ nos pacientes com baixa auto-estima, 53,85\% nos pacientes com média auto-estima e $53,85 \%$ nos pacientes com alta auto-estima; com variações respectivamente dadas por, 2 a 26, 0,42 a 38, 0,06 a 47. De acordo com a análise dos intervalos de confiança de $95 \%$, não há diferença estatisticamente significativa entre as médias citadas. 
A Tabela 1 exibe a distribuição dos Escores de auto-estima, que variam de 0 a 15 pontos.

Tabela 1 - Distribuição do Escore de AE dos pacientes atendidos no Ambulatório de Sequelas de Queimaduras (São Paulo, 2002)

\begin{tabular}{lcc}
\hline Variável & \multicolumn{2}{c}{ Distribuição } \\
\hline Escore de & $\mathbf{n}^{\mathbf{o}}$ & $\%$ \\
AE & & \\
\hline 0 a 5 & 15 & 18,75 \\
6 a 10 & 26 & 32,50 \\
11 a 15 & 39 & 48,75 \\
Média (DP) & $9,91(3,74)$ & \\
IC 95\% & $9,91+0,83$ & \\
Variação & 1 a 15 & \\
\hline
\end{tabular}

Na Tabela 1 agrupamos os pacientes de acordo com a pontuação alcançada (baseados na classificação de auto-estima), assim aqueles que apresentam um escore que varia entre 0 a 5 pontos $(18,75 \%)$ encontram-se no grupo de baixa $\mathrm{AE}$, de 6 a 10 pontos no grupo de média $\mathrm{AE}(32,05 \%)$ e de 11 a 15 pontos no grupo de alta $\mathrm{AE}(48,75 \%)$. A variação do escore é de 0 a 15, com média de 9,91 $(\mathrm{DP}=3,74)$. Podemos concluir então, que a maioria dos pacientes entrevistados $(48,75 \%)$ apresentam um alto escore de auto-estima.

$\mathrm{Na}$ análise das respostas obtidas durante as entrevistas, percebemos uma diferença em relação à concordância ou não com as frases da escala de Dela Coleta, Dela Coleta ${ }^{(15)}$ nas afirmações 11 ("Há coisas em mim que eu gostaria de mudar, se fosse possível") e 12 ("Sinto necessidade de reconhecimento e aprovação dos meus atos"), portanto fizemos um teste para ver se havia relação ou diferença significativa entre as respostas dadas e a auto-estima dos pacientes, que se encontra na Tabela 2.

Tabela 2 - Distribuição das variáveis das respostas às afirmações 11 e 12 , segundo a classificação da AE (São Paulo, 2002)

\begin{tabular}{lcccccccc}
\hline Variável & \multicolumn{9}{c}{ Distribuição } \\
& \multicolumn{1}{c}{ Baixa } & AE & \multicolumn{2}{c}{ Média AE } & \multicolumn{2}{c}{ Alta AE } & \multicolumn{2}{c}{ Total } \\
\hline Res11 & $\mathrm{n}^{\text {o }}$ & $\%$ & $\mathrm{n}^{\text {o }}$ & $\%$ & $\mathrm{n}^{\text {o }}$ & $\%$ & $\mathrm{n}^{\text {o }}$ & $\%$ \\
\hline Erro & 14 & 93,33 & 23 & 88,46 & 23 & 58,97 & 60 & 75,00 \\
Acerto & 1 & 6,67 & 3 & 11,54 & 17 & 41,03 & 20 & 25,00 \\
\hline Res12 & & & & & & & & \\
\hline Erro & 14 & 93,33 & 19 & 73,08 & 15 & 38,46 & 48 & 60,00 \\
Acerto & 1 & 6,67 & 7 & 26,92 & 24 & 61,54 & 32 & 40,00 \\
\hline
\end{tabular}

A análise da Tabela 2 nos mostra que os pacientes com maiores escores de auto-estima apresentaram porcentagem mais elevada de acertos nas questões 11 e 12 (41,03\% e 61,54\%, respectivamente), quando comparados aos pacientes com média e baixa auto-estima, o que pode significar que pessoas com alto nível de auto-estima estão satisfeitas consigo mesmas, ou seja, não têm a necessidade de mudar algo em si mesmas e não sentem a necessidade de que outras pessoas reconheçam os seus atos, apesar da alteração da imagem corporal.

A Tabela 3 exibe os coeficientes de correlação entre as variáveis quantitativas do estudo.

Tabela 3 - Correlação entre variáveis de interesse ${ }^{(a)}$ para todos os pacientes do estudo (São Paulo, 2002)

\begin{tabular}{|c|c|c|c|c|}
\hline Variável & $\mathbf{A E}$ & Idade & T Queim & N Queim \\
\hline $\mathrm{AE}$ & 1,00 & & & \\
\hline Idade & 0,01 & 1,00 & & \\
\hline Tempo de Queimadura & $-0,04$ & 0,03 & 1,00 & \\
\hline Número de Queimaduras & $-0,05$ & $-0,01$ & $-0,14$ & 1,00 \\
\hline Sexo $(1=M)$ & $0,25^{*}$ & $-0,31^{*}$ & $-0,22^{*}$ & 0,06 \\
\hline $\operatorname{Resp11}(1=\mathrm{ac})$ & $0,47^{*}$ & 0,09 & 0,08 & $-0,16$ \\
\hline $\operatorname{Resp} 12(1=\mathrm{ac})$ & $0,46^{*}$ & $-0,16$ & 0,01 & $-0,11$ \\
\hline
\end{tabular}

* Correlação estatisticamente significativa $(p<0,05)$
A auto-estima e o não-verbal dos pacientes com queimaduras (a) A correlação entre as variáveis quantitativas e qualitativas dicotômicas, foi avaliadas pelo Teste de Mann Whitney. 
Milena Froes da Silva Maria Júlia Paes da Silva
O exame dos resultados contidos na Tabela 3 sugere correlação positiva estatisticamente significativa entre AE e Sexo, à Resposta da afirmação 11 e Resposta à afirmação 12 ; sugere correlação negativa estatisticamente significativa entre Idade e Sexo e entre Tempo de Queimadura e Sexo. Assim, há evidência estatística de que pacientes do sexo masculino, que não tem necessidade de mudança pessoal (questão 11) e que não tem necessidade de reconhecimento pessoal (questão 12), tendem a apresentar maiores escores AE; há também evidência de que pacientes do sexo masculino tendem a apresentar menores idades e menos tempo de queimadura, nesse ambulatório. $\mathrm{O}$ Teste Qui quadrado não mostrou evidência de associação estatisticamente significativa entre o sexo e a necessidade de mudança pessoal (questão 11) ou a necessidade de reconhecimento pessoal (questões 12) $(\mathrm{p}>0.05)$ e tampouco entre as necessidades de mudança e reconhecimento (questões 11 e 12) ( $p>0.05)$.

É importante ressaltar, que durante as entrevistas percebemos coerência e espontaneidade na maneira de responder as afirmações por parte dos pacientes, pois estávamos conscientemente registrando o não-verbal expresso e, como Branden ${ }^{(10)}$ afirma, estas são algumas das características das pessoas com boa auto-estima, ou seja, projeção de prazer no rosto, no mover e no falar; ca- pacidade de oferecer e receber elogios; maior abertura às críticas; espontaneidade; harmonia; flexibilidade; maior domínio dos sentimentos de insegurança e ansiedade. É quando o eu interior está de acordo com o eu manifesto no mundo.

Quanto ao segundo objetivo, que foi identificar os sinais não-verbais emitidos pelos pacientes quando questionados sobre sua auto-estima, que complementassem, contradissessem ou demonstrassem sentimentos, os dados são apresentados na Tabela 4.

De acordo com a Tabela 4, percebemos que a categoria de sinais não-verbais que foi observada com maior freqüência, durante as entrevistas, foi o complemento do verbal. Segundo a observação feita, entendemos que a complementação da fala, através do nãoverbal, é fidedigna, pois $\mathrm{Silva}^{(7)}$ afirma que quando uma pessoa fala espontaneamente mostra uma movimentação corporal e facial sincronizada com a modulação da própria voz. O não-verbal expresso pelo corpo, face, tom de voz, entre outros, tem um papel crucial no significado que atribuímos a nossa fala, assim, quando há sinceridade no discurso, o tom de voz, a expressão facial e o olhar, por exemplo, confirmam o que é dito, ou seja, eles complementam o discurso. É como se juntos dissessem: "Sim, é isto o que eu penso!"

Tabela 4 - Sinais não-verbais emitidos pelos pacientes em cada afirmação e detectados pela pesquisadora, segundo sua função, em relação à classificação de Silva (1996) (São Paulo, 2002)

\begin{tabular}{ccccccccccccccccc}
\hline $\begin{array}{c}\text { Afirmações } \\
\text { Sinais }\end{array}$ & $\mathbf{1}$ & $\mathbf{2}$ & $\mathbf{3}$ & $\mathbf{4}$ & $\mathbf{5}$ & $\mathbf{6}$ & $\mathbf{7}$ & $\mathbf{8}$ & $\mathbf{9}$ & $\mathbf{1 0}$ & $\mathbf{1 1}$ & $\mathbf{1 2}$ & $\mathbf{1 3}$ & $\mathbf{1 4}$ & $\mathbf{1 5}$ & Total \\
\hline $\begin{array}{c}\text { Complementar } \\
\text { o verbal }\end{array}$ & 75 & 76 & 73 & 77 & 66 & 72 & 72 & 61 & 73 & 76 & 72 & 72 & 70 & 74 & 71 & 1080 \\
\hline $\begin{array}{c}\text { Demonstrar } \\
\text { Sentimentos }\end{array}$ & 32 & 36 & 13 & 10 & 16 & 18 & 10 & 28 & 30 & 24 & 23 & 18 & 29 & 26 & 19 & 332 \\
\hline $\begin{array}{c}\text { Contradizer o } \\
\text { verbal }\end{array}$ & - & 1 & 2 & 1 & 11 & 6 & 6 & 18 & 4 & 3 & 6 & 5 & 8 & 2 & 4 & 77 \\
\hline \multicolumn{1}{c}{ Total } & 107 & 113 & 88 & 88 & 93 & 96 & 88 & 107 & 107 & 103 & 101 & 95 & 107 & 102 & 94 & 1489 \\
\hline
\end{tabular}

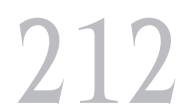

Rev Esc Enferm USP 2004; 38(2):206-16.
Percebemos que as 3 afirmações onde os pacientes mais se expressam complementarmente são:

- $2^{\circ}$ afirmação - "Freqüentemente eu penso que sou um sujeito sem valor."

- $4^{\circ}$ afirmação - "Eu desisto muito facilmente das coisas que estou fazendo."
- $10^{\circ}$ afirmação - "Até hoje pouco consegui realizar do que havia planejado para mim."

Nestas três afirmações os pacientes fizeram uso do olhar, do tom de voz firme e do meneio positivo ou negativo da cabeça, a fim de assegurarem a veracidade das suas respostas. 
A categoria demonstração de sentimentos aparece em segundo lugar, o que não é um indicativo da dificuldade de expressão dos sentimentos por parte dos entrevistados, pois de acordo com Viscott ${ }^{(17)}$, os sentimentos são a maneira como nos percebemos, a nossa reação ao mundo que nos circunda e essa perspectiva apreendida é singular, ou seja, está de acordo com o que a pessoa está se defrontando. Para o autor, os sentimentos devem derivar - basicamente do que está acontecendo agora, o que não implica, necessariamente, na sua demonstração, pois cada um de nós pode apresentar reações diferentes diante daquilo que pensa ser importante.

As 3 afirmações nas quais mais sentimentos foram demonstrados são:

- $1^{\circ}$ afirmação - "Eu costumo ter a sensação de que não há nada que eu possa fazer direito."

- $2^{\circ}$ afirmação - "Freqüentemente eu penso que sou um sujeito sem valor."

-9 ${ }^{\circ}$ afirmação - "Gostaria de encontrar uma pessoa que pudesse resolver meus problemas para mim."

Nas três afirmações a demonstração de sentimentos deu-se através do olhar e do tom de voz baixos, pois foi por intermédio desses suportes que os pacientes expressaram tristeza.

Percebemos poucas contradições no discurso dos pacientes, o que pode demonstrar uma possível honestidade nas respostas da maioria dos entrevistados; porém, 3 afirmações nos chamou a atenção entre os resultados obtidos, pois nelas reduziam o tom de voz, se tornavam sérios na expressão facial, não utilizavam os meneios positivos da cabeça ou gestos que ilustrassem, complementando as afirmações. Essas foram:

• $5^{\circ}$ afirmação - "Sinto-me feliz como sou."

- $8^{\circ}$ afirmação - "Geralmente, eu estou satisfeito comigo mesmo."

-13a afirmação - "No todo, eu estou inclinado a sentir que sou um fracasso."

O que muito nos intrigou foi que, ao longo da entrevista, estes pacientes que demonstraram contradição, seguiam num ritmo semelhante de reações faciais e corporais frente às afirmações, condizentes com a fala, porém diante das afirmações $5^{\circ}, 8^{\circ}$ e $13^{\circ}$ apresentaram uma reação nãoverbal inversa ao que a fala afirmava, como a mudança do tom e ritmo da voz, o olhar voltado para o chão e a inclinação lateral da cabeça.

Para a emissão dos sinais não-verbais, os pacientes utilizaram-se de determinados suportes, ou seja, o olhar, o tom de voz, o meneio da cabeça, o sorriso, a expressão facial, o movimentos dos MMSS, a pausa/ silêncio, a postura corporal e o abaixar de cabeça, que nos deu a sustentação necessária à interpretação feita. Dentre estes suportes, percebemos que os mais utilizados na emissão dos sinais não-verbais foram o olhar, o tom de voz e o meneio da cabeça. Estes suportes foram responsáveis tanto pela complementação do não-verbal como pela contradição do mesmo ou demonstração dos sentimentos. O olhar foi utilizado para enfatizar as respostas dadas (olhar sustentado), contradizê-las (olhar curto ou de soslaio) e demonstrar sentimentos (olhar cabisbaixo, olhos brilhantes ou choro, por exemplo). Davis ${ }^{(8)}$ e Silva ${ }^{(9)}$ afirmam que uma pessoa pode expressar muitas coisas através do olhar, que encarar o próximo que fala pode significar concordância ou, simplesmente, atenção. Assim como podem transmitir atitudes e sentimentos, os movimentos oculares podem também expressar a personalidade. Na verdade há muita sabedoria popular relacionada com o movimento dos olhos; estudos revelam que a pessoa descontente evita o olhar do próximo, da mesma forma que também se olha menos quando se faz uma pergunta pessoal do que quando se pergunta algo de cunho geral ${ }^{(9)}$.

O tom de voz foi o segundo suporte mais utilizado pelos entrevistados, que complementou a fala (tom de voz firme ou baixo), a contradisse (tom de voz fraco ou que denotava desânimo) e demonstrou sentimentos. O tom de voz que é usado em um diálogo indica-nos qual é o sentido do mesmo, pois segundo Davis ${ }^{(8)}$ e Silva ${ }^{(7)}$, a maneira como se pronuncia a mensagem, influi mais na sua avaliação do que o conteúdo verbal propriamente dito. $\mathrm{O}$ meneio da cabeça também foi bastante usado, o que contribuiu, principalmente, para complementar o verbal. Davis ${ }^{(8)}$ relata que numa conversa, o
A auto-estima e o não-verbal dos pacientes com queimaduras 
Milena Froes da Silva Maria Júlia Paes da Silva indivíduo mexe a cabeça a cada grupo de sentenças, normalmente quando acaba de expor um assunto.
Os sentimentos demonstrados pelos pacientes durante a entrevista estão expressos na Tabela 5.

Tabela 5 - Sentimentos demonstrados pelos pacientes em cada afirmação e detectados pela pesquisadora durante as entrevistas (São Paulo, 2002)

\begin{tabular}{|c|c|c|c|c|c|c|c|c|c|c|c|c|c|c|c|c|}
\hline Afirmações & $1^{a}$ & $2^{a}$ & $3^{a}$ & $4^{a}$ & $5^{a}$ & $6^{a}$ & $7^{\mathrm{a}}$ & $8^{a}$ & $9^{a}$ & $10^{\mathrm{a}}$ & $11^{a}$ & $12^{\mathrm{a}}$ & $13^{a}$ & $14^{\mathrm{a}}$ & $15^{\mathrm{a}}$ & Tota \\
\hline \multicolumn{17}{|l|}{ Sentimentos } \\
\hline $\begin{array}{l}\text { Tristeza/ } \\
\text { Decepção }\end{array}$ & 12 & 14 & 8 & 3 & 13 & 12 & 2 & 8 & 16 & 15 & 8 & 11 & 13 & 17 & 10 & 162 \\
\hline $\begin{array}{l}\text { Satisfação/ } \\
\text { Alegria }\end{array}$ & 1 & 2 & 3 & 1 & 3 & 4 & 6 & 7 & 4 & 4 & - & 1 & 3 & 2 & 3 & 44 \\
\hline Insatisfação & - & 1 & 1 & 1 & 2 & 1 & - & 10 & 1 & 1 & 11 & - & - & - & 3 & 32 \\
\hline Segurança & 6 & 4 & - & 1 & - & - & 2 & - & 2 & 1 & - & 1 & 4 & 1 & - & 22 \\
\hline $\begin{array}{l}\text { Timidez/ } \\
\text { Vergonha }\end{array}$ & 7 & 3 & 1 & 3 & - & - & - & 1 & 3 & - & 1 & - & - & 1 & - & 20 \\
\hline $\begin{array}{l}\text { Dúvida/ } \\
\text { Insegurança }\end{array}$ & 4 & - & - & 3 & - & - & - & 1 & - & - & - & 2 & 2 & - & 2 & 14 \\
\hline Ansiedade & - & - & - & - & - & - & 1 & 1 & 4 & 1 & 4 & 3 & - & - & - & 14 \\
\hline Surpresa & - & - & 2 & 1 & - & - & - & - & 1 & 1 & - & - & 6 & 3 & - & 14 \\
\hline Raiva & 2 & 1 & - & - & - & - & - & - & - & 1 & 1 & 1 & - & 1 & 2 & 9 \\
\hline Desconfiança & - & - & - & - & - & 1 & - & - & - & - & - & - & - & - & - & 1 \\
\hline Total & 32 & 25 & 15 & 13 & 18 & 18 & 11 & 28 & 31 & 24 & 25 & 19 & 28 & 25 & 20 & 332 \\
\hline
\end{tabular}

Como podem observar, agrupamos alguns sentimentos, como tristeza/decepção, que são sentimentos chamados "negativos" e, segundo a observação feita, foram os mais demonstrados. Os suportes mais usados para a demonstração desses sentimentos foram o tom de voz baixo, postura da cabeça e olhar (incluindo o choro). Viscott ${ }^{(17)}$ afirma que a tristeza é um sentimento de esgotamento que segue a mágoa ou a perda e que quando as pessoas se sentem tristes e perguntam a si mesmas: "O que foi que perdi?" ou "Como foi que fiquei magoado?", normalmente, surge uma resposta que faz sentido, ou seja, elas podem manifestar sua raiva, mágoa ou dor por causa da sua perda. Quando porém as pessoas ficam tristes por muito tempo, sem compreender o que é que sua mágoa significa, perdem contato, freqüentemente, com o acontecimento que causou a tristeza e o resultado disso é a depressão.

Esses sentimentos, quando negados ou não extinguidos, ganham espaço dentro do indivíduo que os vivencia, fazendo com que este amplie essa não-realização pessoal para as diversas áreas da sua vida. Assim, toda e qualquer atuação sua poderá ser comprome- tida, o que desencadeará uma sensação de incapacidade frente aos obstáculos da vida e é neste ambiente que a tristeza é gerada. Tristeza por estar insatisfeito consigo mesmo, por não estar realizado, por se sentir incapaz.

Mesmo que a maioria dos entrevistados tenham apresentado alta ou média auto-estima, isso não quer dizer que, diante de algumas afirmações, essas pessoas não demonstraram tristeza. Muitos, motivados pelas afirmações, relembraram episódios tristes de suas vidas, que muito os magoaram e, nesses momentos, ficaram tristes. Entre as mulheres a demonstração desse sentimento foi mais evidente e muitas delas choraram durante a entrevista.

A tristeza apareceu mais nas afirmações $2^{\circ}$ (Freqüentemente eu penso que sou um sujeito sem valor.), $9^{\circ}$ (Gostaria de encontrar uma pessoa que pudesse resolver meus problemas para mim.), $10^{\circ}$ (Até hoje pouco consegui realizar do que havia planejado para mim) e $14^{\circ}$ (Eu certamente, me sinto inútil às vezes). Já a insatisfação ficou mais evidente através das respostas negativas dadas pelos pacientes 
nas afirmações $8^{\circ}$ (Geralmente, eu estou satisfeito comigo mesmo) e $11^{\circ}$ (Há coisas em mim que eu gostaria de mudar, se fosse possivel).

\section{CONCLUSÕESE CONSIDERAÇÕES FINAIS}

De acordo com o primeiro objetivo, percebemos que os pacientes atendidos no Ambulatório de Seqüelas de Queimaduras do HC-FMUSP possuem idade variando de 15 a 88 anos, com maior incidência na faixa de 15 a 29 anos (47,50\%); que 54 pacientes $(67,50 \%)$ são do sexo feminino e 26 $(32,50 \%)$ do sexo masculino; que o local de queimadura mais freqüente são os MMSS $(21,91 \%)$ seguido do Tórax $(17,13 \%)$; que o tempo de queimadura apresentado varia de 0,06 a 47 anos, tendo como média 0,06 a $10,05 \operatorname{anos}(56,05 \%)$ e que o número de queimaduras por paciente varia entre 2 a 4 locais $(56,25 \%)$.

Quanto à auto-estima, percebemos que 15 pacientes $(18,75 \%)$ apresentam baixa auto-estima, 26 pacientes $(32,50 \%)$ média auto-estima e 39 pacientes $(48,75 \%)$ alta auto-estima; que a única correlação positiva estatisticamente foi com o sexo, pois de acordo com as porcentagens apresentadas na Tabela 4, os pacientes do sexo masculino apresentam os maiores escores de auto-estima. Esses achados nos surpreenderam, pois inferimos que talvez pacientes com queimaduras na face, pudessem apresentar baixa auto-estima, porém hoje entendemos que o tempo de queimado, o tipo de acompanhamento feito após o incidente e o apoio familiar recebido, podem minimizar esse fato, fazendo com que a pessoa reaprenda a gostar de si mesma apesar da alteração física. Mais uma vez ressaltamos, que durante as entrevistas percebemos coerência e espontaneidade na maneira de responder as afirmações por parte dos pacientes, pois estávamos atentas ao não-verbal expresso.

Para o segundo objetivo, concluímos que o complemento foi a função dos sinais não-verbais mais freqüente entre os pacientes durante as entrevistas, sendo visualizado num total de 1080 vezes; que os suportes mais utilizados para a emissão dos sinais não verbais foram o olhar (626 vezes), o tom de voz (615 vezes) e o meneio da cabeça (237 vezes) e que o sentimento mais demonstrado durante as entrevistas foi a tristeza/decepção (162 vezes).

Fazer este trabalho ajudou a perceber o quanto estar atento à linguagem não-verbal pode facilitar na compreensão do outro ser humano. Por ser uma linguagem silenciosa, podemos até tentar ignorá-la por não nos interessar compreender o outro ou, até, manter o nosso próprio ponto de vista, porém ela não deixa de existir e, quando quisermos realmente entender alguém, ela precisa ser percebida e valorizada.

Davis $^{(8)}$ ressalta que na ausência de regras para a comunicação, qualquer um de nós tem a tendência de ver só aquilo que quer e de prestar atenção somente naquilo que nos convêm. Enquanto, portanto, profissionais da saúde, não podemos ser egoístas, imaginando que o mundo a nossa volta é somente aquilo que queremos ver, pois à medida que aumenta o nosso conhecimento sobre os sinais não-verbais emitidos e cresce a nossa sensibilidade, encontraremos um novo tipo de participação, ou seja, uma outra forma de ver e entender esse interlocutor que está a nossa frente no dia-a-dia.

\section{REFERÊNCIAS}

(1) Dicionário Larousse da Língua Portuguesa. São Paulo: Nova Cultural; 1992.

(2) Stefanelli MC. Comunicação interpessoal. In: Anais do $2^{\circ}$ Simpósio Brasileiro de Comunicação em Enfermagem; 1990 maio 2-4; Ribeirão Preto. Ribeirão Preto: Escola de Enfermagem de Ribeirão Preto/USP; 1990. p. 50-72.
(3) Bueno SMV, Vietta EP. Contribuição e conceptualização de saúde. [Apresentado no $1^{\circ}$ SIBRACEn; 1988 maio 2-4; Ribeirão Preto].

(4) Enoki H, Ferraz AEP, Carvalho EC, Manzial MHP. A produção científica acerca da comunicação em enfermagem. R.P.(Apresentado no $38^{\circ}$ Congresso Brasileiro de Enfermagem, 1986 out 20-4; Rio de Janeiro).
A auto-estima e o

não-verbal dos

pacientes com

queimaduras 
Milena Froes da Silva

Maria Júlia Paes da Silva
(5) Fávero M, Laus E, Nakao JRS, Évora YDM. A importância da comunicação como instrumento administrativo: especial referência à anotação de enfermagem. Rev Paul Hosp 31 (1 e 2): 4-7, 1983.

(6) Mendes IAC. Interação verbal em situação de enfermagem hospitalar: enfoque humanístico. [tese] Ribeirão Preto(SP): Escola de Enfermagem de Ribeirão Preto/USP; 1986.

(7) Silva MJP. Construção e validação de um programa sobre comunicação não verbal para enfermeiros. [tese]São Paulo(SP): Escola de Enfermagem da USP; 1993.

(8) Davis F. A comunicação não-verbal. São Paulo: Summus; 1979.

(9) Silva MJP. Comunicação tem remédio: a comunicação nas relações interpessoais em saúde. $5^{\text {a }}$ ed. São Paulo: Gente; 1996.

(10) Branden N. Auto-estima: como aprender a gostar de si mesmo. $18^{a}$ ed. São Paulo: Saraiva; 1995.

(11) Happé R. Consciência é a resposta. São Paulo: Talento; 1997.
(12) Sapountzi-Krepia DS, Valavanis J, Panteleakis GP, Zangana DT, Sapkas GS. Perceptions of body image, happiness and satisfaction in adolescentes wearing a Boston brace for scoliosis treatment. J Adv Nurs 2001; 35(5):683-90.

(13) Duarte Junior JF. O que é beleza. $3^{\mathrm{a}}$ ed. São Paulo: Brasiliense; 1991.

(14) Andrade D, Angerami ELS. A auto-estima em adolescentes com e sem fissuras de lábio e/ou palato. Rev. Latino-am Enferm 2001; 9(6):37-41.

(15) Dela Coleta JA, Dela Coleta MF. Escalas para medida de atividade e outras variáveis psicossociais. Ribeirão Preto: Escola de Enfermagem de Ribeirão Preto/ USP; 1996.

(16) Berquó ES, Souza JMP, Gotlied SLD. Bioestatística. São Paulo: EPU; 1981.

(17) Viscott D. A linguagem dos sentimentos. São Paulo: Summus; 1982. 